\title{
OMISSÃO DE MACRONUTRIENTES NO CRESCIMENTO E NO ESTADO NUTRICIONAL DE CAPIM-ELEFANTE (CV. MOTT) CULTIVADO EM SOLUÇÃO NUTRITIVA ${ }^{1}$
}

\section{MACRONUTRIENTS OMISSION AND THE GROWTH AND NUTRITIONAL STATUS OF ELEPHANT GRASS (CV. MOTT) GROWING IN NUTRIENT SOLUTION}

\author{
Cíntia Carla AVALHAES ${ }^{2}$ \\ Renato de Mello PRADO ${ }^{3}$ \\ Danilo Eduardo ROZANE ${ }^{2}$ \\ Liliane Maria ROMUALDO ${ }^{2}$ \\ Marcus André Ribeiro CORREIA ${ }^{2}$
}

\begin{abstract}
RESUMO
Objetivou-se avaliar o efeito da omissão de macronutrientes no desenvolvimento e no estado nutricional de plantas de capim-elefante (Pennisetum purpureum Shum cv. Mott). O experimento foi desenvolvido na FCAV/UNESP, em Jaboticabal-SP com o uso de solução nutritiva. O delineamento experimental foi inteiramente casualizado, com sete tratamentos (solução completa Hoagland \& Arnon (1950) e a omissão individual de N, P, K, Ca, Mg e S nessa solução). Após o brotamento dos colmos, as plantas foram colocadas em vasos $\left(5 \mathrm{dm}^{3}\right)$, contendo solução nutritiva sob aeração constante, aplicando-se os tratamentos com três repetições cada. Semanalmente, avaliou-se a altura das plantas, o número de folhas, o diâmetro do colmo e número de perfilhos, além do estado nutricional. A omissão de $\mathrm{N}, \mathrm{P}, \mathrm{K}, \mathrm{Ca}, \mathrm{Mg}$ e S limitaram a produção de massa seca da parte aérea do capim-elefante, em relação ao tratamento completo. A deficiência de um macronutriente, além de promover diminuição do seu teor na parte aérea, resultou em redução da acumulação da maioria dos macronutrientes, com conseqüente alterações morfológicas, traduzidas como sintomas característicos de deficiência.
\end{abstract}

Palavras-chave: Pennisetum purpureum Shum; forrageira; desordem nutricional.

\begin{abstract}
The objective of this work was to evaluate the effect of omission of macronutrients in the growth and the nutritional state of elephant-grass plants (Pennisetum purpureum Shum cv. Mott). The experiment was developed in the FCAV/UNESP, in Jaboticabal-SP,Brazil, using nutrient solution. The experimental design was completely randomized blocks, with seven treatments (the complete solution proposed by Hoagland \& Arnon (1950) and the individual omission of $\mathrm{N}, \mathrm{P}, \mathrm{K}, \mathrm{Ca}, \mathrm{Mg}$ and $S$, in these solution), in three repetitions. Pre-germinated plants were placed in pot $\left(5 \mathrm{dm}^{3}\right)$, containing the nutrient solution, which was aerated constantly during the experimental period and the respective treatments, with three replications each. Weekly, the height of the plants, the leaf number, apex diameter and number of tillers were evaluated as well as plant nutritional state. The omission of $\mathrm{N}, \mathrm{P}, \mathrm{K}, \mathrm{Ca}, \mathrm{Mg}$ and $\mathrm{S}$ limited the production of dry weight of shoot the elephant grass, compared to the full treatment. The deficiency of a macronutrient, in addition to promoting reduction of its content in the shoot, resulted in reducing the accumulation of most macronutrients, with resultant morphological changes, translated as characteristic symptoms of deficiency.

Key-words: Pennisetum purpureum Shum; forage; nutritional disorders.
\end{abstract}

\footnotetext{
${ }^{1}$ Trabalho apresentado na Reunião Brasileira de Fertilidade do Solo e Nutrição De Plantas (FERTBIO), 2008, Londrina - PR.

2 Pós-graduanda em Agronomia (Ciência do Solo), Departamento de Solos e Adubos, Faculdade de Ciências Agrárias e Veterinárias, Universidade Estadual Paulista Júlio de Mesquita Filho. E-mail: cintiavalhaes@hotmail.com; danilorozane@yahoo.com.br; lilianeromualdo@yahoo.com.br; marcus.agro@hotmail.com.

${ }^{3}$ Prof. Dr., Depto. de Solos e Adubos, Faculdade de Ciências Agrárias e Veterinárias, Universidade Estadual Paulista Júlio de Mesquita Filho. E-mail: rmprado@fcav.unesp.br.
} 
AVALHAES, C.C. et al. Omissão de macronutrientes no crescimento...

\section{INTRODUÇÃO}

Entre as gramíneas tropicais, o capimelefante (Pennisetum purpureum Shum.) destaca-se pela alta produtividade, qualidade, palatabilidade, vigor e persistência (Souza Sobrinho et al., 2005). Pode ser usado sob diversas formas (capineira, pastejo, silagem etc.) (Botrel et al., 2000), apresentando características favoráveis como alto rendimento de massa seca, perfilhamento, ótima relação lâmina:colmo com alta qualidade como forragem. Além disso, por apresentar sistema radicular bem desenvolvido, é uma planta que pode contribuir de forma eficiente para aumentar o conteúdo de matéria orgânica do solo (Urquiaga et al., 2006).

A composição química da forragem varia em função da idade, da parte da planta (lâmina ou colmo), da época do ano e da fertilidade do solo. Desses, destaca-se a fertilidade do solo, que pode ser manipulada por intermédio de adubação (Andrade et al., 2003).

Apesar da importância do capim-elefante na pecuária brasileira, estudos sobre a nutrição mineral dessa forragem, envolvendo omissão de nutrientes, e seus reflexos nos teores e acúmulos dos nutrientes na planta, no crescimento e nos sintomas de deficiência ainda são escassos.

A deficiência ou excesso de um nutriente proporciona efeitos semelhantes em diferentes espécies vegetais, devido à similaridade de suas funções (Meyer et al., 1983). No entanto, é comum existir, respostas diferenciadas entre e dentro de espécies como resultado da expressão genética, influenciando a distribuição dos nutrientes (Vose, 1963).

A técnica de cultivo de plantas em solução nutritiva tem permitido avanços no conhecimento da nutrição das plantas, pois controla mais adequadamente a composição da solução e elimina a heterogeneidade e complexidade presente no solo.

Neste contexto, objetivou-se com o presente trabalho avaliar o desenvolvimento, a produção de massa seca e o estado nutricional das plantas de capim-elefante cultivado em solução nutritiva, em função de omissões individuais de macronutrientes.

\section{MATERIAL E MÉTODOS}

$O$ experimento foi conduzido em casa de vegetação, na FCAV/UNESP campus JaboticabalSP, com coordenadas geográficas $21^{\circ} 15^{\prime} 22^{\prime \prime}$ Sul, $48^{\circ} 18^{\prime} 58^{\prime \prime}$ Oeste e altitude de $575 \mathrm{~m}$. A forrageira utilizada foi o capim-elefante (Pennisetum purpureum cv. Mott), em vasos com $5 \mathrm{dm}^{3}$ de solução nutritiva.

Utilizou-se um delineamento inteiramente casualizado, com sete tratamentos e três repetições. Os tratamentos foram os seguintes: 1 - completo (N, P, K, Ca, Mg, S, B, Cl, Cu, Fe, Mn, Mo e Zn); 2 - omissão de nitrogênio (-N); 3 - omissão de fósforo (-P); 4 - omissão de potássio $(-K)$; 5 - omissão de cálcio (-Ca); 6 - omissão de magnésio (-Mg); 7 - omissão de enxofre (-S).
As plantas foram obtidas por propagação vegetativa, a partir de colmos com uma gema, que emergiram em bandejas plásticas contendo areia grossa, posteriormente transplantadas para vasos de polipropileno contendo solução nutritiva completa de Hoagland \& Arnon (1950), diluída a um quarto da concentração usual, mantidos por sete dias. Em seguida, os colmos foram transferidos para a mesma solução diluída a um terço da solução nutritiva, contendo o respectivo tratamento, mantidos por quinze dias. Após esse período, até o final do experimento, utilizou-se a mesma solução nutritiva sem a diluição com substituição por nova partida a cada quinze dias.

Ressalta-se que para o manejo das soluções nutritivas ao longo do período de estudo, o pH foi monitorado diariamente, ajustado-se a $5,5 \pm 0,5$, usando-se solução $\mathrm{NaOH}$ ou $\mathrm{HCl} 0,1 \mathrm{~mol} \mathrm{dm}^{-3}$. Para a reposição da água evapotranspirada foi utilizada água desionizada, sendo a solução nutritiva oxigenada constantemente.

As plantas foram colhidas após cinco semanas da transplantação, exceto as plantas que receberam o tratamento com omissão de enxofre e o completo, sendo estas colhidas na sexta semana após o transplante para os vasos, pois já era possível visualizar a sintomatologia de deficiência nutricional. A forragem foi lavada com água desionizada e separado em parte aérea e raízes, colocado para secar em estufa de ventilação forçada a $65^{\circ} \mathrm{C}$ até massa constante. Após a secagem a forragem foi pesada e moída em moinho tipo Willey para a análise química, determinando-se os teores dos macronutrientes na massa seca da parte aérea e das raízes, conforme método descrito por Bataglia et al. (1983). Com os resultados da massa seca da parte aérea e raízes e os respectivos teores de nutrientes, realizou-se o cálculo do acúmulo desses nutrientes na planta. Durante todo o período experimental, registrou-se a sintomatologia de deficiência nutricional nas plantas inerente a cada tratamento.

Determinou-se a altura das plantas, medida da base da solução até o ápice da maior folha, o diâmetro dos colmos, obtidos a $2 \mathrm{~cm}$ do colo da planta no perfilho principal, bem como o número total de folhas na planta. Realizou-se a análise estatística dos resultados a partir da análise de variância, comparando-se as médias através do teste de Tukey $(p<0,05)$, utilizando-se o software SAS (SAS Institute, 1996).

\section{RESULTADOS E DISCUSSÃO}

\section{Nitrogênio}

A omissão de nitrogênio influenciou o número de folhas, a altura das plantas e o diâmetro do colmo, em relação ao tratamento completo (Tabela 1). O efeito da omissão do $\mathrm{N}$ afetando as características de crescimento avaliadas é amplamente relatado na literatura, sendo o nutriente que mais limita o crescimento e a produção das gramíneas (Prado \& Franco, 2007). 
AVALHAES, C.C. et al. Omissão de macronutrientes no crescimento...

TABELA 1 - Parâmetros vegetativos das plantas de capim-elefante (cv. Mott), em função da omissão de macronutrientes na solução nutritiva.

\begin{tabular}{|c|c|c|c|c|c|c|c|}
\hline \multirow[b]{2}{*}{ Tratamentos } & \multirow{2}{*}{$\begin{array}{l}\text { Altura } \\
(\mathrm{cm})\end{array}$} & \multirow{2}{*}{$\begin{array}{l}\text { Diâmetro } \\
(\mathrm{mm})\end{array}$} & \multirow{2}{*}{$\begin{array}{c}\mathrm{N}^{\circ} \text { de } \\
\text { Folhas } \\
\text { (por planta) }\end{array}$} & \multirow{2}{*}{$\begin{array}{c}\mathrm{N}^{\circ} \text { de } \\
\text { Perfilhos } \\
\text { (por planta) }\end{array}$} & \multicolumn{3}{|c|}{ Matéria seca (g planta ${ }^{-1}$ ) } \\
\hline & & & & & $\begin{array}{l}\text { Parte } \\
\text { aérea }\end{array}$ & Raízes & $\begin{array}{l}\text { Planta } \\
\text { inteira }\end{array}$ \\
\hline Completo & $88,3 b$ & $13,96 a$ & $46 a$ & $10 \mathrm{~b}$ & $26,23 a$ & $2,19 a$ & $28,42 a$ \\
\hline$-N$ & $35,5 f$ & $5,27 e$ & $5 d$ & $1 e$ & $0,50 d$ & $0,34 \mathrm{bc}$ & $0,84 c$ \\
\hline$-P$ & $41,0 \mathrm{e}$ & $8,00 d$ & $6 d$ & $1 e$ & $1,24 \mathrm{~cd}$ & $0,66 b$ & $1,90 \mathrm{c}$ \\
\hline$-\mathrm{K}$ & $79,0 \mathrm{c}$ & $8,66 \mathrm{~cd}$ & $12 c$ & $3 d$ & $2,30 \mathrm{~cd}$ & $0,20 c$ & $2,50 \mathrm{c}$ \\
\hline - $\mathrm{Ca}$ & $40,5 \mathrm{e}$ & $9,66 c$ & $24 b$ & $19 a$ & $2,97 \mathrm{c}$ & $0,41 b c$ & $3,38 c$ \\
\hline$-M g$ & $56,5 d$ & $6,00 \mathrm{e}$ & $25 b$ & $6 c$ & $2,29 c d$ & $0,16 c$ & $2,45 c$ \\
\hline$-S$ & $96,0 a$ & $11,64 b$ & $27 b$ & $6 c$ & $15,84 b$ & $2,46 a$ & $18,3 b$ \\
\hline C.V. $(\%)$ & 3,4 & 5,9 & 5,7 & 8,9 & 11,1 & 13,8 & 11,5 \\
\hline DMS & 4,18 & 1,28 & 4,30 & 1,97 & 2,20 & 0,41 & 2,57 \\
\hline
\end{tabular}

Médias seguidas da mesma letra não diferem significativamente entre si pelo teste de Tukey $(p<0,05)$

Saraiva \& Carvalho (1991) avaliando adubação em capim-elefante, observaram que a omissão do nitrogênio causou decréscimo na produção de massa seca dessa forrageira. Da mesma forma, há relatos sobre o efeito positivo da aplicação de nitrogênio no incremento da produção de forragem do capim-elefante (Andrade et al., 2003; Márquez et al., 2007).
No tratamento completo observou-se teor de $\mathrm{N}$ na parte aérea de $24,5 \mathrm{~g} \mathrm{~kg}^{-1}$, enquanto que no tratamento com omissão deste nutriente, obtevese um valor de $11,7 \mathrm{~g} \mathrm{~kg}^{-1}$ (Tabela 2), abaixo da faixa considerada adequada para o capim-napier, que é de 15 a $25 \mathrm{~g} \mathrm{~kg}^{-1}$, segundo Werner et al. (1997).

Tabela 2 - Teores de nutrientes na massa seca da parte aérea e raiz das plantas de capim-elefante (cv. Mott) em função da omissão de macronutrientes na solução nutritiva.

\begin{tabular}{|c|c|c|c|c|c|c|}
\hline \multirow{3}{*}{ Tratamentos } & $\mathrm{N}$ & $\mathrm{P}$ & $\mathrm{K}$ & $\mathrm{Ca}$ & $\mathrm{Mg}$ & $S$ \\
\hline & ------ & & ----------- & --------. & -------- & ---- \\
\hline & \multicolumn{6}{|c|}{ Parte aérea } \\
\hline Completo & $24,5 d$ & $9,3 b$ & $66,3 b c$ & $2,4 b$ & $2,6 c$ & $1,9 c$ \\
\hline$-N$ & $11,7 e$ & $6,1 \mathrm{c}$ & $93,0 a$ & $5,3 a$ & $3,5 c$ & $1,2 d$ \\
\hline$-P$ & $42,9 b$ & $0,5 d$ & $34,5 d$ & $5,4 a$ & $3,1 c$ & $3,8 a$ \\
\hline$-\mathrm{K}$ & $48,6 a$ & $14,9 a$ & $12,6 e$ & $5,1 a$ & $7,2 a$ & $2,6 b$ \\
\hline - Ca & $47,3 a$ & $11,7 b$ & $77,7 b$ & $0,0 c$ & $4,6 b$ & $3,5 a$ \\
\hline - Mg & $31,3 c$ & $11,1 b$ & $91,7 a$ & $3,1 b$ & $0,4 d$ & $2,2 \mathrm{bc}$ \\
\hline$-S$ & $23, d$ & $6,0 \mathrm{c}$ & $58,3 c$ & $3,0 b$ & $3,1 \mathrm{c}$ & $0,9 d$ \\
\hline C.V. (\%) & 4,6 & 10,8 & 6,8 & 14,2 & 9,4 & 11,6 \\
\hline \multirow[t]{2}{*}{ DMS } & 3,45 & 2,75 & 12,69 & 1,31 & 0,96 & 0,63 \\
\hline & \multicolumn{6}{|c|}{ Raízes } \\
\hline Completo & $22,6 c$ & $5,5 b$ & $7,9 d$ & $0,2 b$ & $5,2 b$ & $5,6 a$ \\
\hline$-N$ & $8,0 e$ & $1,3 c$ & $13,5 b c$ & $0,1 b$ & $2,9 c$ & $1,6 c$ \\
\hline$-P$ & $18,9 d$ & $0,4 c$ & $15,2 b$ & - & $1,4 \mathrm{ef}$ & $4,3 b$ \\
\hline$-\mathrm{K}$ & $26,6 b$ & $17,9 a$ & $1,6 e$ & $8,2 a$ & $2,8 \mathrm{~cd}$ & $3,4 b$ \\
\hline - $\mathrm{Ca}$ & $32,5 a$ & $6,7 b$ & $17,0 \mathrm{~b}$ & - & $1,8 \mathrm{de}$ & $6,4 a$ \\
\hline - Mg & $20,6 \mathrm{~cd}$ & $6,8 b$ & $55,5 a$ & $1,1 b$ & $0,4 f$ & $6,4 a$ \\
\hline$-S$ & $22,9 c$ & $6,7 b$ & $9,0 \mathrm{~cd}$ & $1,6 \mathrm{~b} 0$ & $6,3 a$ & $1,6 c$ \\
\hline C.V. (\%) & 5,1 & 19,6 & 8,5 & 36,7 & 13,2 & 13,9 \\
\hline DMS & 2,74 & 3,26 & 4,72 & 1,69 & 1,03 & 1,25 \\
\hline
\end{tabular}

Médias seguidas da mesma letra não diferem significativamente entre si pelo teste de Tukey $(p<0,05)$

( - ) Material insuficiente para se realizar a análise química. 
AVALHAES, C.C. et al. Omissão de macronutrientes no crescimento...

Nas raízes, também se observou menor teor de $\mathrm{N}\left(8,0 \mathrm{~g} \mathrm{~kg}^{-1}\right)$ para as plantas cultivadas na omissão de $\mathrm{N}$ em comparação ao tratamento completo (22,6 $\mathrm{g} \mathrm{kg}^{-1}$ ) (Tabela 2), o que refletiu no $\mathrm{N}$ acumulado pelas mesmas $\left(49,6 \mathrm{mg}\right.$ planta $^{-1}$ no tratamento completo e $2,7 \mathrm{mg}^{\text {planta }}{ }^{-1}$ na omissão) (Tabela 3).

TABELA 3 - Nutrientes acumulados na massa seca da parte aérea e raiz das plantas de capim-elefante (cv. Mott) em função da omissão de macronutrientes na solução nutritiva.

\begin{tabular}{|c|c|c|c|c|c|c|}
\hline \multirow{3}{*}{ Tratamentos } & $\mathrm{N}$ & $P$ & $\mathrm{~K}$ & $\mathrm{Ca}$ & $\mathrm{Mg}$ & $\mathrm{S}$ \\
\hline & \multicolumn{6}{|c|}{ mg planta ${ }^{-1}$} \\
\hline & \multicolumn{6}{|c|}{ Parte aérea } \\
\hline Completo & $642,7 a$ & $244,8 a$ & $1740,8 a$ & $63,9 a$ & $68,2 a$ & $50,6 a$ \\
\hline$-N$ & $5,8 \mathrm{e}$ & $3,1 d$ & $46,7 \mathrm{c}$ & $2,7 \mathrm{~cd}$ & $1,7 \mathrm{~d}$ & $0,6 \mathrm{~d}$ \\
\hline$-P$ & $52,9 \mathrm{de}$ & $0,6 \mathrm{~d}$ & $42,5 \mathrm{c}$ & $6,7 \mathrm{~cd}$ & $3,8 d$ & $4,7 \mathrm{~cd}$ \\
\hline$-K$ & $134,4 \mathrm{c}$ & $41,5 c$ & $35,5 \mathrm{c}$ & $14,2 \mathrm{c}$ & $20,2 \mathrm{c}$ & $7,3 \mathrm{~cd}$ \\
\hline - $\mathrm{Ca}$ & $140,8 c$ & $34,7 \mathrm{~cd}$ & $229,8 \mathrm{c}$ & $0,1 d$ & $13,8 \mathrm{~cd}$ & $10,5 b c$ \\
\hline$-M g$ & $71,0 \mathrm{~d}$ & $25,5 \mathrm{~cd}$ & $208,8 \mathrm{c}$ & $7,1 \mathrm{~cd}$ & $1,1 d$ & $5,1 \mathrm{~cd}$ \\
\hline$-S$ & $363,9 b$ & $95,7 b$ & $924,6 b$ & $48,0 \mathrm{~b}$ & $49,6 b$ & $15,0 \mathrm{~b}$ \\
\hline $\begin{array}{l}\text { C.V. (\%) } \\
(\%)\end{array}$ & 11,2 & 23,9 & 15,7 & 22,6 & 23,0 & 22,4 \\
\hline \multirow[t]{2}{*}{ DMS } & 57,20 & 37,30 & 227,10 & 13,60 & 15,60 & 7,40 \\
\hline & \multicolumn{6}{|c|}{ Raízes } \\
\hline Completo & $49,6 a$ & $12,1 \mathrm{~b}$ & $17,2 a b$ & $0,4 \mathrm{bc}$ & $11,4 b$ & $12,4 a$ \\
\hline$-N$ & $2,7 d$ & $0,4 c$ & $4,5 \mathrm{~cd}$ & $0,0 \mathrm{c}$ & $1,0 \mathrm{c}$ & $0,5 \mathrm{e}$ \\
\hline$-P$ & $12,5 b c$ & $0,3 c$ & $10,1 b c$ & - & $0,9 c$ & $2,8 \mathrm{bc}$ \\
\hline$-K$ & $5,3 \mathrm{bcd}$ & $3,6 \mathrm{c}$ & $0,3 d$ & $1,6 b$ & $0,6 \mathrm{c}$ & $0,7 \mathrm{de}$ \\
\hline - $\mathrm{Ca}$ & $13,4 \mathrm{~b}$ & $2,7 \mathrm{c}$ & $7,0 \mathrm{~cd}$ & - & $0,8 \mathrm{c}$ & $2,6 \mathrm{bcd}$ \\
\hline$-M g$ & $3,3 \mathrm{~cd}$ & $1,1 \mathrm{c}$ & $8,9 c$ & $0,2 \mathrm{bc}$ & $0,1 \mathrm{c}$ & $1,0 \mathrm{cde}$ \\
\hline$-S$ & $56,3 a$ & $16,5 a$ & $22,1 a$ & $3,9 a$ & $15,4 a$ & $3,9 b$ \\
\hline C.V. (\%) & 17,3 & 25,8 & 26,4 & 55,2 & 22,3 & 23,5 \\
\hline \multirow[t]{2}{*}{ DMS } & 9,64 & 4,36 & 7,58 & 1,58 & 3,10 & 2,00 \\
\hline & \multicolumn{6}{|c|}{ Planta inteira } \\
\hline Completo & $692,3 a$ & $256,9 a$ & $1757,9 a$ & $64,3 a$ & $79,6 a$ & $63,0 a$ \\
\hline$-N$ & $8,7 e$ & $3,5 d$ & $51,2 \mathrm{~cd}$ & $2,7 \mathrm{~cd}$ & $2,7 c$ & $1,1 d$ \\
\hline$-P$ & $65,4 \mathrm{de}$ & $0,9 d$ & $52,6 \mathrm{~cd}$ & $6,7 \mathrm{~cd}$ & $4,7 \mathrm{bc}$ & $8,5 \mathrm{~cd}$ \\
\hline$-K$ & $139,7 \mathrm{~cd}$ & $45,1 \mathrm{c}$ & $35,8 d$ & $15,8 \mathrm{c}$ & $20,8 \mathrm{~b}$ & $8,0 \mathrm{~cd}$ \\
\hline - $\mathrm{Ca}$ & $154,2 \mathrm{c}$ & $37,4 \mathrm{~cd}$ & $236,8 c$ & $0,1 d$ & $14,6 \mathrm{bc}$ & $13,1 \mathrm{bc}$ \\
\hline$-M g$ & $74,3 \mathrm{de}$ & $26,6 \mathrm{~cd}$ & $217,7 \mathrm{~cd}$ & $7,3 \mathrm{~cd}$ & $1,2 \mathrm{c}$ & $6,1 \mathrm{~cd}$ \\
\hline$-S$ & $420,2 b$ & $112,2 b$ & $946,7 b$ & $51,9 b$ & $65,0 a$ & $18,9 b$ \\
\hline C.V. (\%) & 11,1 & 21,7 & 15,5 & 22,4 & 21,9 & 21,3 \\
\hline DMS & 74,32 & 38,86 & 186,14 & 13,5 & 17,20 & 9,83 \\
\hline
\end{tabular}

Médias seguidas da mesma letra não diferem significativamente entre si pelo teste de Tukey $(p<0,05)$

( - ) Material insuficiente para se realizar a análise química. 
AVALHAES, C.C. et al. Omissão de macronutrientes no crescimento...

Além disso, a omissão do nitrogênio afetou o teor de $\mathrm{P}\left(6,1 \mathrm{~g} \mathrm{~kg}^{-1}\right)$, com redução significativa, em comparação com tratamento completo na parte aérea. Por outro lado, aumentaram os teores de $\mathrm{Ca}\left(5,3 \mathrm{~g} \mathrm{~kg}^{-1}\right)$ e $\mathrm{K}(93 \mathrm{~g}$ $\mathrm{kg}^{-1}$ ) no tratamento com omissão de $\mathrm{N}$ em relação ao completo (Tabela 2). Todavia, houve redução das quantidades acumuladas de todos os nutrientes estudados, na parte aérea e na planta inteira, como pode ser observado na Tabela 3 .

Como a omissão do nitrogênio afetou as variáveis de crescimento e também o estado nutricional, houve desenvolvimento de sintomas visuais nas plantas, como o amarelecimento das folhas velhas. Segundo Malavolta et al. (1997) este sintoma está associado com a menor produção de clorofila, ocasionando modificação nos cloroplastos. As plantas apresentaram, ainda, folhas de tamanho reduzido. Quando o crescimento é subótimo, o crescimento é retardado; o $\mathrm{N}$ que está mobilizado nas folhas adultas é translocado para as mais novas, ocorrendo os sintomas típicos de deficiência, tais como o aumento na senescência de folhas mais velhas (Marschner, 1995).

\section{Fósforo}

Os parâmetros vegetativos indicativos de crescimento de capim-elefante foram afetados significativamente pela omissão de fósforo em relação ao tratamento completo. Observa-se diminuição do número de folhas, altura da planta, diâmetro do colmo, bem como do número de perfilhos (Tabela 1), resultando em diminuição da produção de massa seca da parte aérea e das raízes das plantas (Tabela 1 ). Resultados que corroboram aos observados por França et al. (1987), ao trabalharem com omissão de macronutrientes na cultura do milheto.

Salienta-se que a aplicação de fósforo na formação da pastagem independentemente da forrageira a ser utilizada, é de fundamental importância, pois promove maior desenvolvimento inicial das plântulas, após a germinação, crescimento de raízes e perfilhamento das plantas (Werner et al., 1968).

Werner \& Haag (1972) observaram diminuição de $96 \%, 94 \%$ e $82 \%$ na massa seca da parte aérea, das raízes e do número de perfilhos de plantas de capim-elefante, respectivamente, cultivado em solução nutritiva com omissão do $P$ em relação ao tratamento completo. Em condições de campo, Saraiva \& Carvalho (1991) observaram diminuição de $60 \%$ na produção de massa seca do capim-elefante quando não foi fornecido fósforo na adubação. Resultados semelhantes da resposta do capim-elefante ao $\mathrm{P}$, foram obtidos por Moreira et al. (2006).

Um efeito importante do fósforo é sua influência positiva na eficiência da adubação nitrogenada (Werner et al., 1968). Pode-se observar (Tabela 3) que o acúmulo de $\mathrm{N}$ na parte aérea em plantas do tratamento completo foi de $642,7 \mathrm{mg}$ planta $^{-1}$, enquanto que na omissão de $\mathrm{P}$ foi de 52,9 $\mathrm{mg}$ planta ${ }^{-1}$. As plantas no tratamento com omissão do elemento apresentaram, ainda, redução significativa em relação ao tratamento completo, do teor de $P$ na parte aérea $\left(9,3\right.$ para $\left.0,5 \mathrm{~g} \mathrm{~kg}^{-1}\right)$ e nas raízes $\left(5,5\right.$ para $0,4 \mathrm{~g} \mathrm{~kg}^{-1}$ ) (Tabela 2 ). Isso mostra que o tratamento com a omissão do fósforo resulta em plantas deficientes, pois a faixa considerada adequada para o capim-elefante está entre 1 e $3 \mathrm{~g}$ $\mathrm{kg}^{-1}$ de $\mathrm{P}$ (Werner et al., 1997).

Werner \& Haag (1972) também observaram em plantas de capim-elefante, diminuição no teor de $\mathrm{P}$ do tratamento completo $\left(6,8 \mathrm{~g} \mathrm{~kg}^{-1}\right)$ e com a omissão de $P\left(0,9 \mathrm{~g} \mathrm{~kg}^{-1}\right)$. Assim, o teor de $P$ na parte aérea da forrageira, no tratamento completo $\left(9,3 \mathrm{~g} \mathrm{~kg}^{-1}\right)$ está acima do descrito por Marschner (1995) que indica teor de $P$ de 3 a $6 \mathrm{~g} \mathrm{~kg}^{-1}$ para otimizar o crescimento da maioria das culturas durante o estádio vegetativo de crescimento.

Pode-se acrescentar que, conforme esperado, a omissão do fósforo, em relação ao tratamento completo, promoveu diminuição do acúmulo desse nutriente na parte aérea $(244,8$ para $0,6 \mathrm{mg}$ planta $^{-1}$ ) e nas raízes (12,1 para $0,3 \mathrm{mg}$ planta $^{-1}$ ), respectivamente (Tabela 3 ).

A omissão de $P$ nas plantas, causou 0 aparecimento de sintomas visuais, como desenvolvimento lento, e folhas mais velhas apresentando com coloração verde escura, com tons roxos na nervura central. As plantas deficientes em fósforo têm seu crescimento retardado devido esse elemento estar ligado a função estrutural e no processo de transferência e armazenamento de energia, afetando vários processos metabólicos como a síntese de proteínas e ácido nucléico (Malavolta, 2006).

\section{Potássio}

As plantas foram afetadas pela omissão de $\mathrm{K}$, tendo altura, número de folhas, diâmetro de colmo, número de perfilhos e massa seca, significativamente inferiores às plantas que receberam o tratamento completo (Tabela 1). A influencia da adubação potássica sobre as taxas de crescimento e desenvolvimento do capim-elefante foi relatada por Mistura et al. (2006), porém estes resultados discordam dos encontrados por Monteiro et al. (1995) trabalhando com capim Brachiaria brizantha cv. Marandu, os quais observaram que a omissão de potássio não proporcionou diminuição significativa na produção de MS e no perfilhamento, em relação ao tratamento completo.

Martins \& Fonseca (1994) ressaltam que a aplicação de potássio reveste-se de grande importância, especificamente quando a utilização da forrageira é feita sob sistema de corte.

A ausência do potássio na solução nutritiva diminuiu os teores desse elemento na parte aérea e raízes, de 12,6 e 1,6 g $\mathrm{kg}^{-1}$, respectivamente, comparado com 0 tratamento completo na parte aérea $\left(66,3 \mathrm{~g} \mathrm{~kg}^{-1}\right)$ e nas raízes $\left(7,9 \mathrm{~g} \mathrm{~kg}^{-1}\right)$, como pode ser visto na Tabela 2 . Esses valores indicam que a planta que não recebeu $\mathrm{K}$ encontrava-se deficiente, considerando os valores como sendo adequados para o capim-elefante, 
AVALHAES, C.C. et al. Omissão de macronutrientes no crescimento...

conforme Werner et. al (1997), numa faixa entre 15 e $30 \mathrm{~g} \mathrm{~kg}^{-1}$.

A omissão de $K$ resultou em diminuição significativa do acúmulo de todos os outros macronutrientes analisados, em relação às plantas que receberam o tratamento completo, exceto o $\mathrm{Ca}$ nas raízes (Tabela 3 ), que teve incremento da absorção. Este aspecto pode ser explicado pela interação entre esses nutrientes, com competição pelos mesmos sítios de absorção (Malavolta et al., 1997).

A omissão do $K$ na solução nutritiva causou sintomas visuais, como clorose nas margens das folhas novas, com as nervuras centrais mais verdes. Passos (1999) cita que o potássio é necessário ao desenvolvimento da clorofila e participa da ativação de várias enzimas. Vicente-Chandler \& Figarella (1962) ao estudarem aplicações de potássio em capim-elefante, observaram que na ausência do $\mathrm{K}$, as plantas apresentaram pontos cloróticos e necrose nas pontas das folhas mais velhas, com redução de estande da área e diminuição da extração do nutriente pela planta, com conseqüente queda na produção de massa seca. Os mesmos autores ressaltam que a omissão de $\mathrm{K}$ fez com que as plantas não respondessem a adubação nitrogenada, embora as plantas tivessem recebido altas doses de $\mathrm{N}$.

\section{Cálcio}

As plantas que não receberam cálcio apresentaram diminuição no número de folhas, na altura da planta e no diâmetro do colmo, em relação ao tratamento completo, o que refletiu na diminuição da produção de massa seca da parte aérea e raízes (Tabela 1). Este resultado corrobora o relato de Haag (1971), o qual observou que a deficiência de $\mathrm{Ca}$ no capim-elefante, afetou o crescimento do colmo, ramos, folhas $e$ as extremidades das raízes, retardando ou paralisando seu crescimento.

Observa-se (Tabela 2) que as plantas submetidas à omissão de $\mathrm{Ca}$ não apresentaram teor do nutriente na parte aérea, enquanto o tratamento completo apresentou o teor de $2,4 \mathrm{~g} \mathrm{~kg}^{-1}$ e $0,2 \mathrm{~g} \mathrm{~kg}^{-1}$, na parte aérea e nas raízes, respectivamente. Isso indica que as plantas encontravam-se deficientes em relação aos teores citados como adequados para o capim-elefante por Werner et al. (1997), entre 3 e $8 \mathrm{~g} \mathrm{~kg}^{-1}$. Da mesma forma, ocorreu com o $\mathrm{Ca}$ acumulado pelas plantas (Tabela 3), com maior acúmulo do nutriente no tratamento completo (parte aérea $=63,9 \mathrm{mg} \mathrm{planta}^{-1}$ e raízes $=0,4 \mathrm{mg}$ planta $\left.{ }^{-1}\right)$, comparado ao tratamento com omissão do macronutriente (parte aérea $=0,1 \mathrm{mg}$ planta $^{-1} \mathrm{e}$ nas raízes não houve material vegetal suficiente para se realizar análise). Também observou-se que a falta do Ca na solução nutritiva provocou diminuição da acumulação dos demais macronutrientes pelo capim-elefante (Tabela 3), tanto pela parte aérea como raízes.

Além disso, as plantas de capim-elefante que receberam tratamento com a omissão de $\mathrm{Ca}$ apresentaram inicialmente colmos com diâmetro maior e retorcido, folhas com as margens recortadas e tortas e também com pontas necróticas. A falta de cálcio é caracterizada pela redução do crescimento de tecidos meristemáticos, sendo observado, primeiramente, nas extremidades em crescimento e folhas mais jovens (Mengel \& Kirkby, 2001), o que corrobora as observações realizadas neste trabalho.

\section{Magnésio}

Em função da omissão do nutriente na solução nutritiva, houve diminuição significativa do número de folhas, do diâmetro de colmo, número de perfilhos e da massa seca das raízes, das folhas e do total da planta cultivada na solução nutritiva com a omissão de Mg (Tabela 1). Observa-se (Tabela 2) que as plantas submetidas à omissão de $\mathrm{Mg}$ apresentaram menor teor do nutriente, na parte aérea $\left(0,4 \mathrm{~g} \mathrm{~kg}^{-1}\right)$ e raízes $\left(0,4 \mathrm{~g} \mathrm{~kg}^{-1}\right)$ em comparação ao tratamento completo na parte aérea $\left(2,6 \mathrm{~g} \mathrm{~kg}^{-1}\right)$ e nas raízes $\left(5,2 \mathrm{~g} \mathrm{~kg}^{-1}\right)$. Comparandose esses valores com os considerados adequados para o capim-elefante, na faixa de 1,5 e $4 \mathrm{~g} \mathrm{~kg}^{-1}$, conforme Werner et al. (1997), nota-se que as mesmas encontravam-se deficientes. Da mesma forma ocorreu com o $\mathrm{Mg}$ acumulado pela parte aérea das plantas, com maior acúmulo do nutriente no tratamento completo $\left(11,4 \mathrm{mg}\right.$ planta $\left.^{-1}\right)$ comparado à omissão do nutriente $\left(1,1 \mathrm{mg} \mathrm{planta}^{-1}\right)$ (Tabela 3).

Houve ainda, incremento nos teores de $\mathrm{N}$ e $\mathrm{K}$ da parte aérea e $\mathrm{K}$ e Ca nas raízes, em função da omissão do $\mathrm{Mg}$ (Tabela 2), porém com diminuição do acúmulo dos macronutrientes na parte aérea e raízes, exceto o $\mathrm{Ca}$ nas raízes (Tabela 3). Provavelmente os incrementos nos teores de $\mathrm{N}$ e $\mathrm{K}$ na parte aérea ocorreram pela concentração do nutriente, pois nenhum nutriente estudado aumentou a acumulação no tratamento com omissão de $\mathrm{Mg}$ em relação ao completo (Tabela 3).

A omissão de magnésio resultou, ainda, no desenvolvimento de sintomas como o murchamento das plantas, e pontos cloróticos entre as nervuras nas folhas mais velhas, seguidos de necrose nas margens das folhas. Os mesmos sintomas foram observados por Monteiro et al. (1995) em plantas de capim Brachiaria brizantha cv. Marandu. Esses resultados estão de acordo com os sintomas descritos por Malavolta (2006). Segundo o mesmo autor, o magnésio é muito móvel no floema e, portanto, redistribui-se facilmente das folhas e tecidos mais velhos para as regiões de maiores exigências, como os meristemas e órgãos de reserva.

\section{Enxofre}

Em decorrência da omissão de $S$, observou-se diminuição significativa da altura, diâmetro do colmo, número de perfilhos e número de folhas, e da massa seca da partes aérea, e da planta inteira, embora não tenha ocorrido diferença significativa na massa seca de raízes, quando 
AVALHAES, C.C. et al. Omissão de macronutrientes no crescimento...

comparado com o tratamento completo (Tabela 1). Van Eys (1985) estudou a aplicação de doses de S em capim-elefante e observaram acréscimo na produção de massa seca de folhas e colmos.

As plantas submetidas à omissão de $S$, apresentaram uma redução significativa nos teores do nutriente (Tabela 2), na parte aérea $\left(0,9 \mathrm{~g} \mathrm{~kg}^{-1}\right) \mathrm{e}$ nas raízes $\left(1,6 \mathrm{~g} \mathrm{~kg}^{-1}\right)$ comparado ao tratamento completo na parte aérea $\left(1,9 \mathrm{~g} \mathrm{~kg}^{-1}\right)$ e raízes $(5,6 \mathrm{~g}$ $\left.\mathrm{kg}^{-1}\right)$. Nota-se que o tratamento com a omissão de $\mathrm{S}$ está deficiente, pois está abaixo da faixa considerada adequada para a cultura do capimelefante, segundo Werner et al. (1997), que é de 1 a $3 \mathrm{~g} \mathrm{~kg}^{-1}$.

O mesmo ocorreu com o $\mathrm{S}$ acumulado pelas plantas, com maior acúmulo no tratamento completo (parte aérea $=50,6 \mathrm{mg}_{\text {planta }}{ }^{-1}$ e raízes $=$ $12,4 \mathrm{mg}$ planta $^{-1}$ ) comparado ao deficiente, com parte aérea com $15 \mathrm{mg}_{\text {planta }}{ }^{-1}$ e raízes com $3,9 \mathrm{mg}$ planta $^{-1}$ (Tabela 3).

A omissão de $S$ afetou outros nutrientes, com redução dos teores de $P$ na parte aérea $(6,0 \mathrm{~g}$ $\mathrm{kg}^{-1}$ ) como descrito na Tabela 2, e reduziu todos os macronutrientes acumulados na planta inteira, exceto para o Mg (Tabela 3), em relação ao tratamento completo.

A menor absorção de enxofre pode explicar a diminuição na produção de massa seca $(36 \%)$ do tratamento com omissão do mesmo (Tabela 1). De acordo com Andrew (1962), a deficiência de enxofre reduz a quantidade de nitrogênio convertida à forma orgânica, resultando em restrição ao crescimento da planta, por conta da proporção entre esses nutrientes nas proteínas. $\mathrm{O}$ teor de $S$ na planta também foi reduzido na omissão de $\mathrm{S}$, sendo que nesse tratamento a relação $\mathrm{N}: \mathrm{S}$ foi maior (24,2 na parte aérea e 14,4 nas raízes) que no tratamento completo (13,6 na parte aérea e 4,0 na raiz). Esse aumento na relação $\mathrm{N}: \mathrm{S}$ na omissão do elemento foi observada por Van Eys (1985), o qual obteve valores de 19,3 e 14,2 em folhas de capim-elefante não adubado e adubado com enxofre, respectivamente.

As plantas deficientes em $S$ apresentaram clorose nas folhas novas, da mesma forma como descrito por Haag (1971), muito semelhante a deficiência de nitrogênio, embora esse sintoma visual tenha sido detectado mais tardiamente quando comparado aos outros tratamentos.

De forma geral, observou-se que no tratamento completo a ordem de extração de nutrientes da parte aérea foi $\mathrm{K}>\mathrm{N}>\mathrm{P}>\mathrm{Mg}>\mathrm{Ca}>\mathrm{S}$; nas raízes foi $\mathrm{N}>\mathrm{K}>\mathrm{P}=\mathrm{S}=\mathrm{Mg}>\mathrm{Ca}$ e, na planta inteira foi $\mathrm{K}>\mathrm{N}>\mathrm{P}>\mathrm{Mg}>\mathrm{Ca}=\mathrm{S}$ como apresentado na Tabela 3.

\section{CONCLUSÕES}

A omissão de $\mathrm{N}, \mathrm{P}, \mathrm{K}, \mathrm{Ca}, \mathrm{Mg}$ e $\mathrm{S}$ limitaram a produção de massa seca da parte aérea do capim-elefante, em relação ao tratamento completo.

A deficiência de um macronutriente, além de promover diminuição do seu teor na parte aérea, resultou em redução da acumulação da maioria dos macronutrientes, com conseqüentes alterações morfológicas, traduzidas como sintomas característicos de deficiência.

\section{REFERÊNCIAS}

1. ANDRADE, A. C. et al. Adubação nitrogenada e potássica em capim-elefante (Pennisetum purpureum Schum. cv. Napier). Ciência e Agrotecnologia, v. 27, número especial, p. 1643-1651, 2003.

2. ANDREW, C. S. Influence of nutrition on nitrogen fixation and growth of legumes. In: COMMONWELTH SCIENTIFIC INDUSTRIAL RESEARCH ORGANIZATION. A review of nitrogen in the tropics with particular reference to pasture. A symposium. Melbourne: CSIRO, 1962. p. 130-146.

3. BATAGLIA, O. C. et al. Métodos de análise química de plantas. Campinas: Instituto Agronômico, 1983. 48 p. (Circular, 78).

4. BOTREL, M. A. et al. Forage potential of news clones of elephantgrass. Revista Brasileira de Zootecnia, v. 29, n. 2, p. 334-340, 2000.

5. FRANÇA, A. F. S.; HAAG, H. P.; CARMELLO, Q. A. C. Nutrição mineral de gramíneas tropicais III. Deficiência de macronutrientes na produção de matéria seca e na composição mineral do milheto forrageiro (Pennisetum americanum). Anais da Escola Superior de Agricultura "Luiz de Queiroz", v. 44, p. 435-451, 1987.

6. HAAG, H. P. Manual de adubação. São Paulo: Associação Nacional para Difusão de Adubos-ANDA, 1971. 256 p.

7. HOAGLAND, D. R.; ARNON, D. I. The water culture method for growing plants without soils. Berkeley: California Agricultural Experimental Station, 1950, $347 \mathrm{p}$.

8. MALAVOLTA, E. Manual de nutrição mineral de plantas. São Paulo: Agronômica Ceres, 2006. 638 p.

9. MALAVOLTA, E.; VITTI, G. C.; OLIVEIRA, S. Avaliação do estado nutricional das plantas. 2. ed. Piracicaba: Potafós, 1997. 319 p.

10. MÁRQUEZ, F. et al. Evaluación de la frecuencia de corte y tipos de fertilización sobre tres genotipos de pasto elefante (Pennisetum purpureum). 1. Rendimiento y contenido de proteína. Zootecnia Tropical, v. 25, n. 4, p. 253-259, 2007.

11. MARTINS, C. E.; FONSECA, D. M. Manejo de solo e adubação de pastagem de capim-elefante. In: SIMPÓSIO SOBRE CAPIM-ELEFANTE, 2., 1994, Juiz de Fora. Anais... Coronel Pacheco: EMBRAPA-CNPGL, 1994. p. 82-115.

12. MARSCHNER, H. Mineral nutrition of higher plants. 2. ed. London: Academic Press, 1995. $889 \mathrm{p}$.

13. MENGEL, K.; KIRKBY, E. Principles of plant nutrition. 5. ed. Dordrecht: Kluwer Academic Publishers, 2001. 849 p.

14. MEYER, B. et al. Introdução à fisiologia vegetal. 2. ed. Fundação Calouste Gulbenkian, 1983. 710 p.

15. MISTURA, C. et al. Disponibilidade e qualidade do capim-elefante com e sem irrigação adubado com nitrogênio e potássio na estação seca. Revista Brasileira de Zootecnia, v. 35, n. 2, p. 372-379, 2006.

16. MONTEIRO, F. A. et al. Cultivo de Brachiaria brizantha Stapf. cv. Marandu em solução nutritiva com omissões de macronutrientes. Scientia Agricola, v. 52, n. 1, p. 135-141, 1995

17. MOREIRA, L. M. et al. Absorção e níveis críticos de fósforo na parte aérea para manutenção da produtividade do capimelefante (Pennisetum purpureum cv. Napier). Ciência e Agrotecnologia, v. 30, n. 6, p. 1170-1176, 2006.

Scientia Agraria, Curitiba, v.10, n.3, p.215-222, May/June 2009. 
AVALHAES, C.C. et al. Omissão de macronutrientes no crescimento...

18. PASSOS, L. P. Fisiologia do capim-elefante: uma revisão analítica. In: PASSOS, L. P., CARVALHO; L. A.; MARTINS, C. E. (Ed.). Biologia e manejo do capim-elefante. Juiz de Fora: Embrapa Gado de Leite, 1999, p. 29-62.

19. PRADO, R. M.; FRANCO, C. F. Omissão de nutrientes no crescimento, na nutrição e nos sintomas visuais em plantas de milho variedade Al - Bandeirante. Revista de Agricultura, v. 82, n. 1, p. 84-97, 2007.

20. SARAIVA, O. F.; CARVALHO, M. M. Adubação nitrogenada e fosfatada para o estabelecimento de capim-elefante em Latossolo Vermelho-Amarelo textura argilosa. Revista Brasileira de Ciência do Solo, v.15, n. 2, p. 201-205, 1991.

21. SAS INSTITUTE. The SAS-system for windows: release 6.11 (software). Cary: Statistical Analysis System Institute, 1996.

22. SOUZA SOBRINHO, F. et al. Avaliação agronômica de híbridos interespecíficos entre capim-elefante e milheto. Pesquisa Agropecuária Brasileira, v. 40, n. 9, p. 873-880, 2005.

23. URQUIAGA, S. C., ALVES, B.; BODDEY, R. Capim elefante: uma nova fonte alternativa de energia. Seropédica: EMBRAPA Agrobiologia, 2006. Disponível em: <http://www.infobibos.com/Artigos/2006_2/capimelefante/lndex.htm> Acesso em: 20 nov. 2007.

24. VAN EYS, J. E. Sulfur fertilization of five tropical forages. 1. Dry matter production and chemical composition. In: INTERNATIONAL GRASSLAND CONGRESS, 15., 1985, Kyoto. Resumos... Kyoto, 1985.

25. VICENTE-CHANDLER, J; FIGARELLA, J. Effects of the nitrogen sources on yields and composition of napier grass. Journal of Agriculture of the University of Puerto Rico, v. 44, n. 2, p. 215-227, 1962.

26. VOSE, P. B. Differences in plant nutrition. Herbage Abstracts, v. 33, n. 1, p.1-13, 1963

27. WERNER, J. C.; HAAG, H. P. Estudos sobre a nutrição mineral de alguns capins tropicais. Boletim de Indústria Animal, v. 29, n. 1, p. 191-245, 1972

28. WERNER, J. C. et al. Forrageiras. In: RAIJ, B. van et al. (Ed.) Recomendações de adubação e calagem para o Estado de São Paulo. 2. ed. Campinas: Instituto Agronômico, 1997. p. 263-273 (Boletim Técnico, 100).

29. WERNER, J. C. et al. Fontes de nitrogênio e seus efeitos na produção forrageira. Boletim da indústria Animal, v. 25 , p.151-159, 1968.

Recebido em 02/04/2008 Aceito em 26/03/2009 